\title{
On the Existing Status in Listening Teaching and Some Suggestions for It*
}

\author{
Xiaorong Luo \\ Foreign Language School, Changchun University of Science and Technology, Changchun, China \\ Email: lxrlinda301@yahoo.com.cn \\ Jian Gao \\ English Department, The Educational Institute of Jilin Province, Changchun, China \\ Email: bobgao1965@yahoo.cm.cn
}

\begin{abstract}
The aim of listening class is to train learner's listening skills, listening is fundamental to language skills. Without listenging, speaking, reading, writing and translating could not be improved. Even so, in modern methods of second language teaching, listening skill is ignored by many teachers in one way or another.In this paper, the author is going to talk about the existing status in Englisn listening teaching in China as the second language, bring about some methods to solve the problems and give a few suggestions in listening teaching.
\end{abstract}

Index Terms - the existing status, skill training, listening teaching, linguistic units, features of listening, micro skills

\section{INTRODUCTION}

The aim of the listening class is to train the listener's listening skill. Yang Huiyuan (1996) believes that the nature of listening comprehension is the process of receiving and decoding linguistic signals by using the auditory organ. While this active and dynamic decoding process is very complex, in which our human brain interprets and reacts to the linguistic signals. It is thought that listeners would analyze and recognize the new linguistic information according to their acquired knowledge after the receptions of the linguistic information by the auditory organ. During this process, listeners would transfer this information into the linguistic units with certain meanings, and then contrast these linguistic units by using the information stored in their brains to interpret and respond to the speaker's meaning.

Listening class is for the second language learners, whose aim is to develop the second language learner's listening skill. Before studying English, learners have mastered the knowledge of their native language (NT), including the knowledge of phonetics, vocabulary, grammar and culture and they have formed the fixed thinking mode by using NT. During their study of English in their native language atmosphere, they don't have the habit of thinking in English, which requires the special training for learners to solve the problems. It is obvious that listening teaching is very important because listening is the most common communicative activity in daily life. According to Morley (1991), "we can expect to listen twice as much as we speak, four times more than we read, and five times more than we write." Therefore, listening, as a skill, is considered to become more and more important in second language or foreign language classroom teaching than ever before. According to some scholars, listening is fundamental in the language teaching and learning, for it offers the learner the input. If the input were not interpreted at the right level, any learning would be impossible. Listening is thus important to speaking. In this paper, the author is going to describe the existing status in listening teaching in China and put forward some training ways to improve listening teaching.

\section{Relative TheORIES ABOUt Listening TEACHING}

\section{A. The Acquisition-learning Hypothesis}

Krashen (1980) suggested that the learner's knowledge of the second language is best characterised in terms of two entirely separate and unrelated competences: 'acquired' knowledge and 'learnt' knowledge. Acquisition refers to a nonconscious process of rule internalization resulting from exposure to comprehensible input when learner's attention is on meaning rather than form and is not depending on the teaching of grammar rules, like what Paradowski(2007) put, acquisition occurs as the subconscious, automatic, spontaneous and incidental picking up and internalisation of language, resulting from natural language use in meaning-focused situations, gradually developing linguistic competence via meaningful exposure to comprehensible input. It consists of subconscious second language rules which are available for automatic processing, serving as the primary source for initiating both the comprehension and

\footnotetext{
* This paper is sponsored by JLPOPSS, with the code of 2010B29
} 
production of utterances; it is also called 'communicative proficiency', which is more common in a second language context. Learning stands for a conscious process involving the study of explicit rules of language and monitoring one's performance and it is the result of conscious study of the formal properties of the language and producing utterances accordingly. It consists of metalinguistic rules which can only be employed sequentially (rather than in parallel) for controlled processing to monitor — or edit — output generated by means of 'acquired' knowledge; it is also called 'academic proficiency'. This process is more typical of classroom learning in a foreign language context.

\section{B. Input Hypothesis}

In language learning, input is the language which a learner hears or receives and from which he or she can learn. The input hypothesis is an idea that exposure to comprehensible input which contains structures that are slightly in advance of a learner's current level of competence is the necessary and sufficient cause of second language acquisition. According to Wikipedia, the free encyclopedia, if $i$ represents previously acquired linguistic competence and extra-linguistic knowledge, the hypothesis claims that we move from $i$ to $i+1$ by understanding input that contains $i+1$. Extra-linguistic knowledge includes our knowledge of the world and of the situation, that is, the context. The +1 represents new knowledge or language structures that we should be ready to acquire.

The comprehensible input hypothesis can be restated in terms of the natural order hypothesis. For example, if we acquire the rules of language in a linear order, then $i$ represents the last rule or language form learned, and $i+1$ is the next structure that should be learned. It must be stressed however, that just any input is not sufficient, the input received must be comprehensible. According to Krashen, there are three corollaries to his theory. The first is that talking (output) is not practicing. Krashen stresses yet again that speaking in the target language does not result in language acquisition. Speaking can indirectly help in language acquisition, but the ability to speak is not the cause of language learning or acquisition. Instead, comprehensible input is the result of language acquisition. The second is that $i+1$ is present when sufficient comprehensible input is provided. That is to say, that if language models and teachers provide enough comprehensible input, then the structures that acquires and are ready to learn will be present in that input. Krashen thinks this is a better way to develop grammatical accuracy than direct grammar teaching. The last is that the teaching order is not based on the natural order. Instead, learners will acquire the language in natural order by receiving comprehensible input.

\section{The Affective Filter Hypothesis}

This is advanced by Krashen and associated with his monitor model of second language development. The hypothesis is based on the theory of an affective filter, which states that successful second language acquisition depends on the learner's feelings. Negative attitudes (including a lack of motivation or self-confidence and anxiety) are said to act as a filter, preventing the learner from making use of input, and thus hindering success in language learning.

\section{The Features of Listening And Existing Status in Listening Teaching}

\section{A. The Features of Listening}

Listening is the most difficult for most Chinese learners of English, which is decided by the features of listening class. On the one hand, listening activity is momentary or flashy. This instant activity and instinctive interpretation are the features of oral communication. When we make the oral communication, the information is conveyed at the speed of around 0.2 seconds for one syllable, which requires listeners to catch the speaker's meaning quickly by intuition. But actually learners usually pay their attention to the phonetic forms rather than their meanings. On the other hand, listeners have no way to control the speaker's speed. Listening is an activity of understanding what the listeners hear, which leads to the fact that the listeners have to follow the speaker's speed because they are passive while listening and have no way to control the speakers. If the speed is fast, the phonetic variations would occur. Therefore, listeners can not identify the sound and its variations. However, if the speed is slow, language would not be cohesive. Listeners may not concentrate themselves on what they hear if there is the break. In this way, learners can not think actively, affecting their understanding what they hear. Besides, learners should identify the isolated phonemes and single words, and what's more, they should identify the sentences and utterances in the flow of speech because the pronunciation of the isolated phonemes and words are quite different from their pronunciation in fast flow of speech.

\section{B. The Existing Status of Listening Teaching}

Listening class has already been a self-governed course in foreign language teaching in China, while the existing teaching status is not satisfied, which is embodied in the following aspects: Firstly, the air of listening class is not active because the learners usually listen to the teachers or records passively so that they are usually not active and creative in learning. Secondly, the content of the listening text is not reasonable for the learners in the aspect of the difficulty level. In China, many college students never contact listening training before their college study while the content of some textbooks is so professional that learners cannot understand them. In a certain degree, the text beyond learners violates the content of the comprehensible input hypothesis. Thirdly, the teaching mode is so single. In listening class, the teacher often plays the record and the listeners are engaged in listening passively to a monologue or speech or even conversation over the radio, CDs, TV, films, lectures etc. and here listener usually doesn't have the opportunity to ask 
for clarification, slower speech or repetition. After listening to the materials, learners usually do some written exercises relating to the record. This mode makes the teachers are tired of teaching and learners are weary of learning. At present, the multimedia equipment has been installed in most universities and colleges in China, but both the teachers and learners never get rid of this playing the record-listening to the record-doing exercise teaching mode. Next, relatively speaking, the time for listening class is not enough. There is only one hour in one week in many universities, leading to the fact that learners have less time to expose to the target language from the angle of hearing. Then, learner's foreign language knowledge, including the knowledge of phonetics, vocabulary, grammar and culture, is not enough, which is the obstacle for listening comprehension. Last but not least, at the moment, the multimedia has been used in most schools, which is advanced and whose purpose is good, but it also results in two negative effects. On the one hand, the students play the computer games and watch movies instead of learning in class. On the other hand, in the multimedia classroom, the teachers usually spend most time controlling the machine so that they have less time and energy to control the class and care for the learner's affection. There is no eye contact and no psychological communication between the learners and teachers, leading to their big psychological distance and making learners' lack of motivation, self-confidence and even anxiety. According to Krashen's affective filter hypothesis, the negative attitudes are said to act as a filter, preventing the learner from making use of input, and thus hindering success in language learning. Ignoring the affective factors of learners by the teachers is the taboo in modern language teaching.

\section{TRAINING FOR LISTENING SKILLS}

According to the analysis of the listening teaching status and its features, it is time for us to attach the importance to it. Lv Bisong(1996) advanced that the task and the function of listening training is to train learner's listening skill, develop their ability to adapt to listening to some information. Zhao Jinming (2007) has the following suggestions about listening teaching: we should start to train the learner's listening skill as early as possible; the listening exercise is the basic way to train the learner's listening skill, which includes phonetic recognition and understanding to the meanings of the utterance; the main ways to improve the skills are the intensive listening, extensive listening and casual listening. The first two ways are often applied in class and the later is used out of class for the learners to study by themselves; we should take some other elements into consideration, that is, the input, storage, retrieval, deduction, transformation and exchange of the information when we talk about the training of listening skill. Nowadays, the listening micro skills have been generally accepted by many scholars. Yang Huiyuan (1996) generalized that the listening micro skills include the ability to identify and analyze the information, the ability to remember and store information, the ability to associate and guess, the ability to respond to the information quickly, the ability to write while listening, the ability to imitate after listening, the ability to retrieve and monitor the information and the ability to generalized and sum up the information. According to Rost (1991), listening comprises some component skills, that is to say, the skills of discriminating between sounds, recognizing words, identifying grammatical groupings of words, identifying expressions and sets of utterances that act to create meaning, connecting linguistic cues to non-linguistic and paralinguistic cues and using background knowledge to predict and later to confirm meaning and recalling important words and ides.

The above is the generalization of listening skills by the scholars, two strategies should be adapted to improving listening skills. In psycholinguistics, cognitive psychology, and information processing, a contrast is made between two different ways in which humans analyze and process language as part of comprehension and learning. One way, known as the bottom-up processing, makes use of the information present in the input to achieve higher level meaning. This means learners or students make use of their linguistic knowledge to identify and analyze the linguistic elements in an order from such smallest linguistic units as phonemes (the bottom) to the largest ones as complete texts (the top). Learners connect the smaller linguistic units to constitute the larger parts and it's a linear process in which they get the meaning automatically in the last stage. This process is text-based where learners depend on the sounds, words and grammar in the message in order to create meaning. The other way, known as the top-down processing, makes use of "high level", nonsensory information to predict or interpret "lower level" information that is present in the data, which requires learners to go to the listening with their prior knowledge of topic, context, and type of text as well as the knowledge of language to reconstruct the meaning by using the sounds as clues. This background knowledge stimulates a series of expectations that aid the listener to understand what is heard and predict what will come next.

The meaning of these two terms varies depending on the unit of analysis. For example, in word recognition, the higher level information is the knowledge of permissible words as well as actual words of a language, while the lower level information is the actual phonetic input (or orthographic input in the case of written word recognition). In sentence comprehension or the interpretation of an utterance, the lower level information is words, while higher level information includes the knowledge of grammar, semantics and pragmatics. As applied to the full understanding of a passage, the lower level information consists of words and sentences, while the higher level information includes the reader's previously existing knowledge of the world, including cultural and moral values, scripts, schemas and literary genres. Generally speaking, the bottom-up process is thought to be used while practicing minimal pairs, taking pronunciation tests, listening for specific details, recognizing cognates and word-order pattern while the top-down interpretation is applied in such activities as listening for the general idea, predicting, drawing inferences, and summarizing what they know and what they hear through listening comprehension. 
The bottom-up and top-down process belongs to the macroscopic view in listening teaching. The specific practices are as follow: training for identifying the information. The aim for this is to cultivate learner's attention and the ability to identify and analyze the information by identifying the sameness and difference, the truth and false; training for listening and loud reading. This is to combine listening and loud reading so that the learners can associate the sound, form with the meaning; training for dictation. Dictation is a very useful and effective way to practice the listening skills, which is thought to be a very important way to check the learner's listening comprehension; training for listening and speaking. The function of this training is to develop the ability of learners to combine their listening and speaking by means of listening and stating what the learners hear, listening and answering the questions that the learners need to answer; training for prediction. This may decrease the difficulty and anxiety for the learners in listening study.

\section{Some SugGeStions FOR Listening TEACHING}

Listening is the most important part in language teaching and learning. Combining the common problems in listening teaching and based on the relative second language learning theory above, the teachers should take the following elements into consideration apart from the skill training:

\section{A. Creating the Ideal Learning Condition for Learners}

According to the acquisition-learning hypothesis, the adult doesn't lose the ability to learn a language. Krashen even thought that the adult may have the stronger ability to learn a language than children do if an ideal learning condition is given. Therefore, in listening teaching, the teachers should create an ideal condition for learners so that learners may know and master what they learn. The so-called ideal conditions are a comfortable and harmonious studying environment and atmosphere, a modest teaching method, explanation of linguistic knowledge of the foreign language. Meanwhile, the conscious listening practice and memory activities should not be ignored.

\section{B. Transferring the Single Teaching Mode into the Interactive Listening Teaching Way}

This means learners study and communicate in foreign language to reach an effective process to learn a language by means of the interact among the teachers, learners and the listening materials. In interactive or reciprocal listening situations listener is required to take part in the interaction and alternately listens and speaks. Interactive listening situations include face-to-face conversations and telephone calls in which listener has an opportunity to ask for clarification, repetition, or slower speech from conversation partner.

\section{Adapting a Learner-centered Approach}

In most cases in China, the teachers are the main speakers in class. And now we have to transmit this situation to make the learners to be the center in class. The teachers should design some activities to make learners involved in learning and make them realize how the language is organized, how the native speakers use the language and how the communication happens.

\section{Making Use of the Positive Function of the Affective Factors.}

This may make learners participate in the activities in class so that the passive listening class may become the active one, which requires that the teachers be good at building up a harmonious relationship between the teacher and learners. Both the teacher and the learners should trust and respect each other. Besides, the teacher should know learner's need and affections to shorten the psychological distance between them. Meanwhile, teachers should behave well to stimulate learner's motivation and develop their good attitude toward learning a foreign language.

\section{E. Improving Listening Teaching by Multichannel Ways.}

Listening class is a self-governed course in foreign language teaching, but it is not isolated and it is the combination of listening class teaching and the relative listening activities in other classes. Besides, we may open such classes as the appreciation of foreign music, film to stimulate learners from the angles of sight and hearing in the aspect of phonetics to reach the purpose of improving listening skills.

\section{F. Attaching the Importance to Training Learner's Communicative Competence}

Having a large quantity of input of language doesn't mean the learners can study the target language well. The task for the teachers is not only to teach learners linguistic knowledge, also to develop learner's communicative competence in target language in class and out of class. Communicative competence is advanced by Hymes, American linguist. Hymes(1970) thought it as the knowledge of not only if something is possible in a language, but also the knowledge of whether it is feasible, appropriate or, done in a particular Speech Community. It includes, 1) formal competence--knowledge of the grammar, vocabulary, phonology and semantics of a language. 2) sociocultural competence--knowledge of the relationship between language and its nonlinguistic context, knowing how to use and respond appropriately to different types of Speech Acts, such as requests, apologies, thanks and invitations, knowing which Address Forms should be used with different persons one speaks to and in different situations, and so forth. 3) discourse competence---knowing how to begin and how to end the conversations. 4)strategic competence---knowledge of communication strategies that can compensate for weakness in other areas. In fact, Hymes' formal competence amounts 
to Chomsky's grammatical competence, the other three are equal to his pragmatic competence. The former refers to linguistic accuracy and the latter the appropriateness when language is used in a certain context. In order to use a foreign language correctly, it is not enough for learners to have some linguistic competence. Generally speaking, learners start to learn a foreign language after they have had the communicative competence in their mother tongue which is certain to affect the foreign language learning. To overcome the interference by MT, the communicative competence in the second language is necessary. In this way, learners may know where to say, what to say and how to say.

\section{G. Attaching the Importance to Improving Learner's Cultural Quality of the Target Language}

Language is inseparable from culture. A particular language is associated with a particular culture, the language provides the key to the understanding of the associated culture, and language itself cannot be really learned or fully understood without enough knowledge of the culture in which it is deeply embedded. Without language, culture would not be possible. On the one hand, languages is influenced and shaped by culture; it reflects culture. In the broadest sense, language is the symbolic representation of a people, and it comprises their historical and cultural backgrounds as well as their approach to life and their ways of living and thinking. What needs to be stressed here is that language and culture interact, and that understanding the language requires understanding the culture. Learning a foreign language well means more than merely mastering the pronunciation, grammar, words and idioms. It also means learning to see the world as native speakers of that language see it, learning the ways in which their language reflects the ideas, customs, and behavior of their society, learning to understand their language of the mind. Learning a language, in fact, is inseparable from learning its culture. So language and culture must be studied together, and great efforts must be made in the study of the culture in which the TL operates. Improving our cultural quality may make our language fluent, vivid, and elegant.

\section{CONCLUSION}

Learners can respond to it only if they receive the information, which means that language learning is decided by listening in a certain degree. Without listening, speaking is impossible. When they receive something by auditory organ, listening gives the learners the aural input so that the language acquisition or learning occurs and makes learners interact in oral communication. Therefore, the effective ways for listening teaching is helpful for learners in language learning. In order to improve learner's listening skill, the teachers have to start from the beginning to cultivate learner's ability to predict, to catch the information. Based on this, the teacher has to give the chance to learners to know the culture of the target language. In this way, learners may improve themselves in language learning.

\section{REFERENCES}

[1] Hymes. D.H. (1970). On communicative competence. in Brumfit, C.J. \& Johnson,K. (eds) (1972),The communicative approach of language teaching. Oxford: OUP.

[2] Input Hypothesis (no date ). http://en.wikipedia.org/wiki/Comprehensible_input.(accessed 24/2/2012).

[3] Longman Dictionary of Language Teaching and Applied Linguistics. (2005). Beijing: Foreign Language Teaching and Research Press.

[4] Luo Xiaorong. (2005). On strategies of college English listening teaching. Journal of Beihua University. 6.5,126-128.

[5] Lv Bisong. (1996). An introduction to teaching Chinese as a foreign language. Beijing: Beijing Language University Press.

[6] Morley J. (1991). Listening comprehension in second/foreign language instruction. In M. Celce-Murcia (Ed.), Teaching English as a second or foreign language (pp. 81-106). Boston, MA: Heinle \& Heinle. From http://www.supremeequipmentwi.com/krashen-monitor-hypothesis/.(accessed 20/2/ 2012).

[7] Pan Lei. (2002). On interference in second language learning. Master's thesis, Jilin university.

[8] Paradowski, Michał B. (2007). Exploring the $\mathrm{L}_{1} / \mathrm{L}_{2}$ Interface. A Study of Polish Advanced EFL Learners. Warsaw : Institute of English Studies, University of Warsaw.

[9] Rod Ellis. (2004). Second language acquisition. Shanghai: Shanghai Foreign Language Education Press.

[10] Rost. M. (1991). Listening in language learning. London: Longman. Web Transcription Tool. http://www.supremeequipmentwi.com/krashen-monitor-hypothesis/

[11] Stephen D. Krashen. (1980). Second language acquisition and second language learning. Shanghai: Shanghai Foreign Language Education Press.

[12] Wang Bixia. (2001). Training for listening skills of HSK. Beijing: Beijing Language University Press.

[13] Yang Huiyuan. (1996). Methodology of Chinese listening and speaking. Beijing: Beijing Language and Culture University Press.

[14] Zhao Jinming. (2007). An introduction to teaching Chinese as a foreign language. Beijing: The Commercial Press.

Xiaorong Luo was born in Changchun, China in 1963. She received her M.A. degree in linguistics from Changchun University of Science and Technology, China in 2009.

She is currently an associate professor in School of Foreign Languages, Changchun University of Science and Technology. Her interests are concerning the fields of language teaching and applied linguistics. She has published some papers relating to her teaching.

Jian Gao was born in Changchun, China in 1965. He got his bachelor degree in English teaching from Siping Teachers' College, 
Siping, Jilin, China in 1984.

He is currently an associate professor in English Department, the Educational Institute of Jilin province, China. His favorite fields are the general linguistics and teaching methodology. His latest publication is The importance of Teaching English Phonetics, and he also did the project on On the differences of Chinese and English Phonetics. 